Mariana Pereira da Silva ${ }^{a}$

Marcia Hespanhol Bernardo ${ }^{\mathrm{a}}$

Heloísa Aparecida Souza ${ }^{a}$

a Pontifícia Universidade Católica de Campinas. Pós-Graduação em

Psicologia. Campinas, SP, Brasil.

Contato:

Mariana Pereira da Silva

E-mail:

mariananox@gmail.com

O trabalho não é baseado em tese e não foi apresentado em reunião científica.

As autoras declaram que o trabalho não foi subsidiado e que não há conflitos de interesses.

\section{Relação entre saúde mental e trabalho: a concepção de sindicalistas e possíveis formas de enfrentamento}

\author{
Relationship between Mental Health and Work: \\ unionists' conception and possible confrontation practices
}

\section{Resumo}

Objetivo: apresentar as concepções de sindicalistas a respeito da relação entre trabalho e adoecimento mental, bem como algumas de suas ações, que possam indicar rumos para abordagens do movimento sindical que favoreçam o enfrentamento do adoecimento mental relacionado ao trabalho. Método: foram realizadas entrevistas reflexivas em profundidade com cinco representantes sindicais de diferentes categorias profissionais, do estado de São Paulo, que possuem um histórico de comprometimento com a saúde dos trabalhadores. Resultados: a concepção predominante entre os sindicalistas entrevistados é de que as causas dos adoecimentos do trabalhador são de caráter multifatorial. Assim, esses líderes sindicais reconhecem a organização do trabalho, os processos produtivos, as relações trabalhistas e as condições físicas do ambiente de trabalho como alguns dos fatores que podem gerar sofrimentos ou adoecimentos psíquicos nos trabalhadores. Discussão: os participantes indicam, como possíveis estratégias de enfrentamento do adoecimento mental provocado pelo trabalho, a união dos trabalhadores e dos sindicatos, o restabelecimento de laços de solidariedade, maior investimento do Estado e conscientização de toda a sociedade a respeito da relação entre a saúde mental e o trabalho.

Palavras-chave: saúde mental; trabalho; sindicatos.

\begin{abstract}
Objective: to present the trade unionists' conceptions regarding the relationship between work and mental illness, as well as some of their actions, that can indicate directions for union's movement approaches that favor the confrontation of work-related mental health. Method: reflective in-depth interviews were conducted with five union leaders who represent different professional categories from the state of São Paulo which are historically committed to workers' health. Results: among the interviewed unionists the predominant conception is that work-related disease has multifactorial causes. They consider work organization, manufacturing processes, labor relations and workplace environmental conditions as some of the factors that can cause workers' mental disorders. Discussion: the participants indicated - as possible strategies to confront work-related mental disorders - the alliance of workers and unions, the reestablishment of solidarity bonds, higher state investments, and consciousness-raising of the whole society regarding the relationship between work and mental health.
\end{abstract}

Keywords: mental health; work; trade unions. 


\section{Introdução}

O mundo do trabalho na contemporaneidade gera impactos significativos na saúde física e mental dos trabalhadores. As diversas mudanças provocadas pela globalização financeira, pelas inovações tecnológicas e pelas novas formas de gestão interferem diretamente no bem-estar dos trabalhadores, na forma como trabalham e, inclusive, na maneira em que se organizam coletivamente.

Franco et al. ${ }^{1}$ apontam que o trabalho na modernidade é marcado pela flexibilização e pela precarização social, ambos possuem diversos aspectos que repercutem negativamente na subjetividade do trabalhador. Segundo as autoras, a precarização no mundo do trabalho é caracterizada por ritmos intensos e aumento da competitividade, falhas na prevenção e diluição das responsabilidades em relação a acidentes de trabalho, falta de reconhecimento e valorização social, fragilização dos vínculos, rupturas de trajetórias profissionais, banalização da injustiça social, dentre outras características que degradam as condições de trabalho e podem levar o trabalhador ao adoecimento físico e mental.

Seligmann-Silva et al. ${ }^{2}$ também ressaltam que o contexto de precarização e flexibilização faz os trabalhadores vivenciarem seu trabalho de forma insegura, altamente competitiva, individualizada e em "tensão permanente", conforme afirma Linhart ${ }^{3}$. Essas condições de trabalho podem conduzir a sérios problemas relacionados à saúde mental, como síndrome de burnout, depressão, suicídios, abuso de álcool e drogas, psicossomatização, workstress, fadigas, entre outros.

Mesmo tratando-se de uma situação que pode ser considerada séria e urgente, as pautas de negociações e lutas dos sindicatos ainda são tímidas com relação aos aspectos referentes à relação entre saúde mental e trabalho, inclusive entre aqueles que, na década de 1980, tiveram uma participação importante na incorporação do campo da Saúde do Trabalhador no Sistema Único de Saúde (SUS) e reconhecem os efeitos deletérios dos modelos de trabalho atuais, conforme se vê em Sato e Bernardo ${ }^{4}$.

Com base nas abordagens da Psicologia social do trabalho e da Saúde mental relacionada ao trabalho (SMRT), foi realizada uma pesquisa que teve como objetivo compreender as concepções de sindicalistas sobre a relação entre saúde mental e trabalho. Os resultados desse estudo mostraram que, no contexto geral, apesar do tema da SMRT ser negligenciado em muitos sindicatos, conforme diversos estudos indi$\mathrm{cam}^{4-7}$, existem sindicalistas sensíveis e comprometidos com a temática. Desse modo, busca-se, neste artigo, apresentar as concepções desses sindicalistas, bem como algumas de suas ações que podem indicar rumos para abordagens do movimento sindical que favoreçam o enfrentamento do adoecimento mental relacionado ao trabalho. Para tal, o texto está organizado da seguinte forma: inicialmente, apresentamos uma reflexão sobre a relação existente entre saúde mental e trabalho e traçamos um rápido panorama do movimento sindical na atualidade brasileira. Em seguida, apresentamos os aspectos metodológicos adotados, para finalizarmos com a discussão dos resultados da pesquisa.

\section{A saúde mental relacionada ao trabalho como um problema de saúde pública}

O crescimento do desgaste mental dos trabalhadores pode ser verificado nas estatísticas oficiais, como as da Organização Mundial de Saúde (OMS) e do Ministério da Previdência Social (MPS). A OMS ${ }^{8}$ mostra que os transtornos mentais podem atingir até $40 \%$ dos trabalhadores, sendo que $30 \%$ são considerados transtornos "menores", e entre 5 e 10\% são de nível grave. Dados do MPS ${ }^{9}$ mostram que os afastamentos por problemas de saúde mental cresceram muito nos últimos anos e que já são a terceira maior causa de afastamento do trabalho no país. Tais dados apontam a relevância em compreender como ocorre o desgaste mental do trabalhador, e quais ações podem ser realizadas pelos sindicatos - enquanto entidades representativas dos trabalhadores - para mudar esse quadro.

Devemos ressaltar que o nexo causal entre desgaste mental e trabalho ainda é um grande desafio. Como apontam Paparelli et al. ${ }^{10}$, é raro que sejam considerados os elementos sociais presentes no processo de saúde/doença psíquica. Assim, as razões do adoecimento são, muitas vezes, atribuídas ao indivíduo, culpabilizando-o e individualizando um problema que é, essencialmente, social. O trabalhador é tratado, nesse sentido, como descuidado e irresponsável frente a acidentes e ao adoecimento, desconsiderando-se pressões, exigências, prazos e outras formalidades que caracterizam o trabalho contemporâneo, especialmente em países de economia dependente como o Brasil e outros da América Latina ${ }^{11,12}$. Além disso, é comum que se entenda o trabalho como algo naturalmente penoso, como se não fosse possível modificar os aspectos que geram adoecimento ao trabalhador.

Em contraposição a essa perspectiva, SeligmannSilva ${ }^{5}$ desenvolve o conceito de "desgaste mental" para analisar o processo de saúde/doença psíquica relacionado ao trabalho. Esse conceito tem origem nas proposições de Laurell e Noriega ${ }^{\mathbf{1 3}}$ sobre a Saúde do Trabalhador. Os autores - utilizando-se da perspectiva dialética do materialismo histórico - buscam 
integrar o processo biopsicossocial saúde/doença, correlacionando poderes e cargas de trabalho vivenciadas pelos trabalhadores. Laurell e Noriega ${ }^{13}$, afirmam que o desgaste pode ser entendido como “a perda da capacidade potencial e/ou efetiva corporal e psíquica do trabalhador”, que pode ou não se expressar no que a medicina reconhece como patologia. Para Seligmann-Silva ${ }^{5}$, o trabalho no capitalismo implica a deformação do corpo e das potencialidades psíquicas. Assim, o componente desgastante no trabalho faz-se maior do que o componente de reposição e de desenvolvimento das capacidades no trabalho. A autora sintetiza,

o desgaste é visualizado como produto de uma correlação desigual de poderes impostos sobre o trabalho e sobre o trabalhador, acionando forças que incidem no processo biopsicossocial saúde-doença. Ou melhor, uma correlação de poderes e forças em que o executante do trabalho torna-se perdedor.

Dessa forma, Seligmann-Silva ${ }^{5}$, baseada na teoria da medicina social latino-americana, mostra-nos que o desgaste é vivenciado pelo trabalhador em situações em que o trabalho consome seu corpo e seu potencial psíquico, devido, principalmente, às cargas de trabalho às quais estão expostos e às condições precárias encontradas nos ambientes de trabalho. No que se refere especificamente ao desgaste mental, a autora afirma tratar-se da integração entre os fatores ambientais e psicossociais, do mundo subjetivo e da identidade do trabalhador em seus micro e macrocontextos, e também das relações de poder presentes em todas as esferas sociais. Assim, além do desgaste físico, há ainda os diversos impactos na saúde mental do trabalhador, que correspondem tanto ao desgaste mental literal - orgânico, que envolve, por exemplo, danos corporais, biológicos e neurológicos devido à exposição a substâncias neurotóxicas - como à fadiga mental e física, que envolve alterações psicológicas e fisiológicas transitórias e cumulativas; e, por fim, desgastes que afetam a subjetividade e a identidade do trabalhador, mediante a corrosão de seus valores e de seu caráter, conforme aponta Sennett ${ }^{14}$.

Tendo como base o que propõe SeligmannSilva $^{5}$, a compreensão do processo de desgaste mental do trabalhador deve considerar a análise de diferentes patamares, que incluem o contexto internacional, os contextos nacionais, as empresas, o espaço microssocial do local de trabalho e as características individuais dos trabalhadores. Desse modo, existem aspectos importantes a serem analisados, tais como o ambiente físico, químico e biológico, as relações de trabalho, relações interpessoais, sistemas sociais, posição no mercado e atual situação da empresa, cultura organizacional, política de pessoal, uso de tecnologias, conjuntura socioeconômica, políticas econômicas e conexas, políticas sociais e intersetorialidade, territorialidade, dentre outras questões. Além disso, a individualidade também é um patamar de análise, que envolve a trajetória histórica e pessoal do trabalhador, que se confronta com os demais patamares por meio de seu trabalho.

Vemos, assim, que a abordagem do desgaste mental, enquanto perspectiva de estudo, rompe com concepções biologicistas e individualizantes. Essa abordagem integra o campo da SMRT, no qual o trabalhador é compreendido como um indivíduo dotado de subjetividade e que está imerso em macro e microcontextos sociais, econômicos e políticos. Com isso, não é possível entender o trabalhador sem que se entenda o seu trabalho, e vice-versa.

Devemos, portanto, compreender a complexidade dos diversos patamares, para que os aspectos do trabalho - que podem afetar a saúde mental do trabalhador - sejam tomados como objetos de reflexão, pois, apesar das discussões e dos estudos sobre o tema, os adoecimentos no trabalho continuam em crescimento, configurando-se como um importante problema de saúde pública na atualidade. Tal fato aponta a importância dos sindicatos, enquanto legítimos representantes dos trabalhadores - inclusive, no âmbito do controle social no SUS - na luta por condições de trabalho menos insalubres.

\section{O campo da Saúde do Trabalhador e os sindicatos}

No Brasil, o campo da Saúde do Trabalhador se desenvolveu no mesmo contexto histórico do ressurgimento do movimento sindical. Em ambos, as reivindicações e a participação dos trabalhadores foram essenciais, refletindo a força das reivindicações sociais que eclodiram no período final da ditadura militar. Nesse período, o movimento sindical, combativo e classista, obteve maior relevância, e a luta pela saúde do trabalhador foi uma das pautas que culminaram em diversas conquistas.

Atualmente, com as contradições do trabalho contemporâneo e sua precarização, tanto as ações reivindicativas do movimento sindical quanto a luta pela saúde dos trabalhadores acabaram por se enfraquecer. De modo geral, podemos dizer que o individualismo e a alta competitividade dentro do âmbito do trabalho, seguindo os valores propagados pelo capitalismo contemporâneo, colaboraram para o enfraquecimento da luta pelo coletivo, que caracterizou a história de muitos sindicatos no Brasil. Nas palavras de Rodrigues ${ }^{15}$ : 
É verdade que o sindicalismo, mesmo vivendo mundialmente uma situação defensiva, bem diferente daquela que era a norma até meados dos anos de 1970, no nível da empresa, dadas certas condições, discute/negocia o tema da participação nos lucros e nos resultados, nas orientações dos investimentos, em alguns casos, notadamente no âmbito da cidade ou da região onde o sindicato está estabelecido, bem como o tema da tecnologia. No entanto, no horizonte do movimento operário ou do sindicalismo - atualmente - o móvel de sua luta é menos a busca pelo controle da produção e pela emancipação socialista a partir do local de trabalho e mais a tentativa de inclusão na chamada sociedade de consumo.

Segundo o autor, as grandes organizações sindicais foram perdendo força e, nesse sentido, a capacidade de confrontação com o capital foi se enfraquecendo. Com a competição do mundo globalizado, a instabilidade e as incertezas econômicas - características da contemporaneidade -, as instituições sindicais foram extremamente desestabilizadas. Rosso ${ }^{16}$ indica que, atualmente, o Brasil possui um alto número de sindicatos de trabalhadores. Em 2012, o Ministério do Trabalho e Emprego registrou 9.954 entidades com certificado ativo, cerca de $8 \%$ a mais do que em 2001. Em um contexto de enfraquecimento do poder de combate sindical, essa fragmentação das entidades revela a busca por espaços políticos, por verbas do imposto sindical, por divisão territorial e por puro corporativismo, e isso, no entanto, não resulta na elevação da capacidade de luta do movimento sindical como um todo.

Tanto Rosso ${ }^{16}$ quanto Rodrigues ${ }^{15}$ afirmam que a postura defensiva e a fragmentação do movimento sindical têm implicado poucas ações propositivas ações que, no máximo, têm sua atenção voltada para a manutenção dos direitos já conquistados. Além disso, a terceirização também colabora para dividir os trabalhadores. Para Sant'Anna ${ }^{b}$, a contratação de funcionários por meio de serviços terceirizados é uma forma de enfraquecer o movimento sindical, já que coloca dentro do mesmo ambiente trabalhadores filiados a diferentes sindicatos, o que acaba por diminuir a coesão grupal ${ }^{17}$.

Lacaz $^{6}$ aponta a fragilidade do movimento sindical na atualidade como um dos elementos que impedem o avanço do campo da Saúde do Trabalhador. Cabe lembrar que, historicamente, o movimento sindical contribuiu muito para as conquistas no âmbito do trabalho, inclusive para a implantação do campo da Saúde do Trabalhador no Brasil. Sendo assim, podemos afirmar a necessidade de fortalecimento dos sindicatos, a fim de que sejam desenvolvidas práticas de enfrentamento da precarização, para que se consiga melhores condições de trabalho e direitos assegurados aos trabalhadores, que possam garantir a preservação de sua saúde, especialmente, de sua saúde mental, que, como já apontado neste texto, fica bastante vulnerável nos modelos de trabalho predominantes na atualidade.

No entanto, um recente documento elaborado pelo Departamento Intersindical de Estatística e Estudos Socioeconômicos (DIEESE) ${ }^{18}$ - ao analisar o conteúdo das cláusulas negociadas e das reivindicações sindicais - sinaliza que a saúde do trabalhador pouco aparece nas pautas. A maior parte da luta sindical ainda se refere a questões salariais e de benefícios. Ao tratar da saúde, as pautas sindicais, no máximo, fazem referência à eliminação de riscos físicos do ambiente de trabalho. A partir desse diagnóstico, a entidade também destaca a necessidade de incorporar as questões da saúde mental dos trabalhadores nas discussões e nas pautas sindicais.

Desse modo, este artigo parte do pressuposto de que a participação dos sindicatos é essencial para que se entenda a complexidade do desgaste mental do trabalhador e se faça frente às condições que o geram, considerando o contexto de flexibilização e precarização no qual o mundo do trabalho está imerso atualmente.

Também levamos em conta as afirmações de Bihr ${ }^{19}$, segundo o qual, os sindicatos devem buscar formas criativas de luta e romper com ações tradicionais. Esse autor afirma que, apesar do sindicalismo passar por uma crise, ele ainda pode ser o principal movimento de emancipação humana nas próximas décadas. Para isso, é necessário que sejam adotadas vias de renovação, que permitam enfatizar os desafios globais a serem superados e tragam reivindicações que sejam dignas de credibilidade, capazes de restabelecer a esperança e a confiança nos trabalhadores, dando origem a um movimento alternativo, diferente do tradicional.

Acreditamos que ações mais criativas, com foco em questões de saúde vivenciadas pelos trabalhadores na atualidade - especialmente a saúde mental poderiam, inclusive, fortalecer os próprios sindicatos junto às suas bases.

\section{Considerações sobre o método da pesquisa}

A pesquisa teve caráter qualitativo e as informações foram obtidas por meio de entrevistas reflexivas em profundidade, como propõe Hammersley e Atkinson ${ }^{20}$. Os entrevistados foram incentivados a falarem livremente, favorecendo, assim, a

b Juiz do Trabalho e presidente da Associação Nacional dos Magistrados da Justiça do Trabalho. 
compreensão de suas concepções a respeito da SMRT e das ações realizadas ou que poderiam ser empreendidas pelos seus respectivos sindicatos sobre questões relativas a esse tema.

Foram realizadas cinco entrevistas com representantes sindicais legitimamente eleitos junto a sindicatos de diferentes categorias profissionais, sendo: professores da rede privada, químicos, bancários, petroleiros e metalúrgicos. Tais sindicatos estão vinculados a diferentes centrais sindicais, entretanto, não iremos fornecer maiores especificidades para garantir o sigilo e o anonimato contratado com os entrevistados. É importante ressaltar, ainda, que a seleção dos participantes se deu de forma intencional. Segundo Duarte ${ }^{21}$, na pesquisa qualitativa, o pesquisador pode escolher os participantes por juízo particular, como conhecimento do tema ou representatividade subjetiva. Assim, buscamos representantes de sindicatos com histórica e reconhecida trajetória na defesa da saúde do trabalhador, priorizando os sindicalistas responsáveis pela área de saúde da entidade, que apresentassem proximidade com esse tema ou que tivessem participado da luta pela construção da Saúde do Trabalhador no Brasil.

A pesquisa foi aprovada por comitê de ética (CAAE: 20792913.1.0000.5481) e, em todas as entrevistas, foi entregue um termo de consentimento livre e esclarecido, que, depois de lido, foi assinado pelos participantes. As entrevistas, realizadas no período de dezembro de 2014 a fevereiro de 2015, tiveram duração entre 45 minutos e 2 horas e 30 minutos e propiciaram rico conteúdo para análise. Com exceção de uma entrevista, que foi realizada no local de trabalho do entrevistado, todas as outras ocorreram nas sedes dos respectivos sindicatos, de forma tranquila, sem interferências significativas. Foram entrevistados três homens e duas mulheres. No entanto, para garantir o anonimato dos sujeitos, optamos por referenciá-los por meio de sua categoria profissional no gênero masculino, o que também simplifica a identificação da filiação dos participantes ao longo do texto.

Os entrevistados trouxeram falas pautadas na vivência com os trabalhadores da sua base, que refletem toda sua experiência no movimento sindical. Um deles, inclusive, chegou a se emocionar, ao longo de suas falas, ao contar sobre sua trajetória profissional e suas experiências com trabalhadores adoecidos.

Por fim, cabe ressaltar que as entrevistas foram gravadas, transcritas e posteriormente analisadas. Basicamente, buscamos atribuir sentido às falas dos participantes entrevistados, relacionando-as com a teoria estudada e com as percepções das pesquisadoras. Essa forma de análise aproxima-se à proposta de
Minayo $^{22}$, que defende a união de elementos da hermenêutica e da dialética, que facilitam a compreensão e interpretação dos textos, das falas e dos depoimentos, como resultado de um processo social e de conhecimento, fruto de múltiplas determinações.

\section{Resultados e discussão}

A apresentação dos resultados da pesquisa divide-se em dois tópicos: um dedicado às concepções dos representantes sindicais a respeito da relação entre saúde mental e trabalho e, outro, às possíveis formas de enfrentamento adotadas na prática sindical em relação ao processo de saúde/adoecimento mental do trabalhador.

\section{Concepções dos representantes sindicais acerca da re- lação entre saúde mental e trabalho}

É interessante destacar que, ao tomarem conhecimento da temática da pesquisa, todos os entrevistados iniciaram suas falas fazendo referência ao contexto social mais amplo e suas análises, na maior parte das vezes, foram próximas ao que se encontra na literatura crítica sobre o tema.

O maior destaque, apresentado por todos os entrevistados, diz respeito ao fato de vivermos em um mundo guiado pela lógica neoliberal, que defende a participação mínima do Estado nas questões sociais e econômicas e cujas características refletem nas relações interpessoais, nos valores das pessoas e, inclusive, na organização e na forma com que o trabalho é concebido. O trabalho assalariado atual foi caracterizado de forma individualizada e competitiva e, além disso, sua crescente precarização gera fortes implicações no processo de saúde/doença do trabalhador. Essas afirmações condizem com os estudos de Franco et al. ${ }^{1}$ e de Bernardo ${ }^{11}$, que discutem o trabalho na contemporaneidade, com características como a flexibilização e a precarização social, que, por sua vez, repercutem na subjetividade e na saúde mental dos trabalhadores.

\section{Conforme destaca o Professor:}

As condições de trabalho estão cada vez mais difíceis para o trabalhador, e estão cada vez mais favorecendo o adoecimento dos docentes, adoecimento tanto mental, psicológico, emocional quanto físico. Estamos vivendo um período de muito individualismo, os professores estão trabalhando muito, eles não têm tempo mais para a assembleia, ou não valorizam mais, porque, politicamente, estão com uma consciência muito rebaixada, estão sobrecarregados de trabalho, então não há tempo para isso. Coletivos que não se reúnem, não pensam sobre sua condição. É fundamental os coletivos se reunirem [...]. A gente adoece com a competitividade entre nós, porque se 
você fica muito obstinado a fazer um caminho muito próprio, você acaba que não vê quem tá ao lado.

Em suas falas, os representantes sindicais apontam a complexidade do contexto de trabalho contemporâneo e, assim, reconhecem que conseguir estabelecer o nexo causal entre trabalho e adoecimento mental é um desafio a ser vencido - o que está de acordo com o que discutem Bernardo e Garbin ${ }^{23}$. Além disso, eles destacam que a organização do trabalho e dos processos produtivos, as relações trabalhistas e as condições físicas do ambiente de trabalho são fatores que podem gerar um desgaste intenso à saúde do trabalhador e prejudicar sua organização coletiva.

Para o Petroleiro, um possível causador de adoecimento, no contexto atual, está nas relações de poder e na competição estabelecidas dentro dos locais de trabalho, com a chefia e com os demais colegas, podendo acarretar em isolamento, assédios, humilhações, dentre outros elementos que podem conduzir os trabalhadores ao sofrimento ou adoecimento mental.

O Bancário e o Petroleiro destacaram também a quebra de laços de solidariedade entre os trabalhadores, decorrente dos modelos de trabalho atuais, como um fator que favorece o adoecimento. Em suas falas, afirmaram que, muitas vezes, as empresas valorizam tanto a competição, que isso se torna o guia dos trabalhadores no desempenho de suas atividades. Assim, eles são estimulados a tentar conquistar cargos e espaços superiores aos dos colegas, mesmo que, para isso, tenham que trapacear e/ou desrespeitar a integridade do outro. O Bancário exemplifica esse aspecto ao se referir às metas que estão muito presentes no setor na atualidade. Segundo ele,

a gente também percebe a quebra dos laços de solidariedade entre os trabalhadores, que pavimenta muito um caminho para a questão do assédio moral. E aí não tem uma reação coletiva dos trabalhadores. De repente, você está muito bem nas metas e eu não, e você começa a ter algum tipo de problema. Eu vou torcer para que você se atrapalhe no meio do caminho, pois nós somos competidores. E tem trabalhador que, agora os bancos possuem uma grande parcela de jovens, que vem muito com essa ideologia, vem muito com essa cara de competição.

É interessante notar o destaque desse entrevistado para o fato de os jovens já chegarem "com essa ideologia" da competição, evidenciando como tal lógica ultrapassa os espaços de trabalho. Esse mesmo sindicalista também afirmou que, além dessas características, atualmente, os bancários acabam se tornando vendedores de serviços oferecidos pelo banco, tais como créditos, cartões, investimentos e seguros. Em uma análise similar a de Sznelwar e Uchida ${ }^{24}$. com relação às centrais de atendimento, o sindicalista apontou que, para atingir a quantidade estipulada, os bancários, muitas vezes, recorrem à venda de produto sem que os clientes tenham pedido, bem como a mentiras ao consumidor, o que acaba por ferir seus valores e sua ética profissional e pessoal.

Tais situações indicam o que Sennett ${ }^{14}$ descreve como "corrosão do caráter", situações que acabam por corromper nossos valores éticos e que podem ser vistas na relação que estabelecemos com nós mesmos e com os demais, enquanto resultado das condições do sistema capitalista. Seligmann-Silva ${ }^{5}$ nos lembra que, além das repercussões sociais, esse contexto também pode provocar sofrimento e afetar a saúde mental dos trabalhadores.

A concepção de que, hoje, é considerado normal ser workaholic também esteve presente na fala de todos os representantes sindicais, revelando preocupação com a intensificação do trabalho. SeligmannSilva et al. ${ }^{2}$ discutem essa questão e apontam que, atualmente, os comportamentos de workaholic ou workaddict são comportamentos esperados dos trabalhadores. A invasão de outros espaços da vida pelo trabalho foi especialmente destacada pelo Professor, para quem o trabalho dos docentes tem imposto cada vez mais a necessidade de realizar atividades fora do local de trabalho - fato que está de acordo com a pesquisa de Bernardo ${ }^{25}$, referente a essa categoria profissional.

Também os representantes dos petroleiros e dos metalúrgicos destacam que existe muita pressão sobre os trabalhadores para alcançarem o maior ritmo de produção possível. As metas fazem parte da organização do trabalho no mundo atual e, de acordo com Bruno ${ }^{26}$, essa pressão vivenciada para atingir os objetivos propostos é uma das principais causas de adoecimento do trabalhador que podem levar à vivência de conflitos morais.

Outro aspecto abordado pelo Bancário refere-se ao fato de muitos trabalhadores irem trabalhar mesmo estando com a saúde mental muito comprometida, devido à cultura do medo que se instaurou nas empresas. $\mathrm{O}$ entrevistado afirmou que, muitas vezes, "os trabalhadores encontram-se presentes em seus locais de trabalho, ainda que estejam deformados por dentro". Segundo ele, o trabalhador toma diversos remédios e, mesmo com o psiquismo muito abalado, continua trabalhando por medo de ficar marcado, de perder benefícios ou de ser demitido. Seligmann-Silva ${ }^{5}$ discute essa condição, denominada "presenteísmo", e afirma que, apesar de se tratar de um sério problema de saúde pública, é pouco conhecida e debatida no Brasil.

As questões da falta de segurança e da violência no trabalho foram abordadas tanto pelo Bancário 
como pelo Petroleiro como importantes geradores de desgaste mental. Segundo o Bancário, os assaltos às agências e aos caixas eletrônicos, cada vez mais comuns, fazem os trabalhadores se sentirem inseguros e desprotegidos em seus locais de trabalho. Esse representante sindical oferece, inclusive, alguns exemplos, como o sequestro de um tesoureiro do banco, que teve sua saúde mental intensamente afetada.

Já o Petroleiro afirmou que, na sua categoria profissional, os trabalhadores de refinarias e de plataformas petroquímicas convivem com diversos riscos, como a exposição a produtos tóxicos, o manejo de equipamentos que, se tiverem falhas, pode resultar em explosões, ferimentos, mortes, dentre outros exemplos. Essa vivência gera uma tensão permanente, tanto com relação à possibilidade de cometerem algum erro que possa gerar consequências graves quanto pela possibilidade de eles mesmos serem vítimas, situação que é corroborada pelos estudos de Alvarez et al. ${ }^{27}$.

O Petroleiro relatou, ainda, que alguns trabalhadores exercem suas atividades nas plataformas de extração de petróleo, que ficam cerca de 300 a 400 quilômetros da costa. Lá, eles estão isolados e em condições mais precárias do que nas refinarias. Isso também pode contribuir com o adoecimento mental desses trabalhadores, conforme destacam Moreno et al. ${ }^{28}$ e Alvarez et al. ${ }^{27}$, que afirmam que, no cenário nacional, as condições de vida nas plataformas são consideradas "perversas" ou de "sacrifício", já que as plataformas, em sua maioria, estão localizadas em áreas de risco. Assim, até tarefas cotidianas, consideradas simples, devem se pautar em procedimentos que envolvam certa rigidez de conduta, o que acaba por desorganizar a vida social dos trabalhadores, desgastando-os física e mentalmente.

Analisando esse contexto, o Petroleiro destaca outro aspecto importante: a forma como se tende a naturalizar esses riscos, como se o trabalho fosse essencialmente perigoso e coubesse apenas ao trabalhador a responsabilidade para prevenir os acidentes. Ele lembra que os riscos são uma criação social. Segundo ele,

é um troço que está sendo desenhado por seres humanos, que está sendo construído e operado por seres humanos, as intervenções são pensadas e executadas por seres humanos, que, em tese, são uns dos melhores técnicos da indústria do país e até mesmo internacionalmente. [...] E essa coisa é tão terrível, tão complexa e perversa que, quando acontece um acidente desse tipo, assim como em várias outras ocasiões, da sociedade em geral, acaba acontecen- do a culpabilização da vítima: "Ah, foi a pessoa que falhou no procedimento. Foi ela que rompeu com o padrão de segurança”. Não, pô. O trabalho tá concebido para ser perigoso, já está totalmente relativizada a questão da proteção absoluta da vida do cara ou não, e aí a culpa é de uma pessoa que foi lá executar o trabalho que era uma rotina?

Como complemento a essa fala, podemos ressaltar as afirmações do Metalúrgico, que diz que as tecnologias, cuja presença é inevitável no mundo do trabalho atualmente, deveriam estar presentes em situações em que os trabalhadores correm risco e em que as condições são insalubres. Assim, poderiam colaborar para garantir qualidade de vida e não para desumanizar ou para produzir ainda mais risco, como, segundo ele, ocorre em grande parte das empresas do seu setor. Essa afirmação encontra perfeita sintonia com o estudo de Praun ${ }^{29}$, que demonstra que a reestruturação dos processos produtivos - incluindo o advento das avançadas tecnologias -, ao contrário do que se esperava, intensificou a degradação do trabalho e da saúde dos trabalhadores.

A questão do trabalho em regime de turnos foi especialmente destacada pelo Petroleiro, o que, segundo ele, compromete muito a vida pessoal do trabalhador, seu lazer e seu descanso, bem como relacionamentos familiares e sociais. Isso pode gerar isolamento, solidão excessiva e prejudicar, portanto, sua saúde. Moreno et al. ${ }^{28}$ afirmam que exercer atividades em horários noturnos e/ou irregulares gera efeitos significativos na saúde e no bem-estar orgânico e social do trabalhador. O Petroleiro complementou sua fala dizendo ter conhecimento, inclusive, de casos de suicídio relacionados ao isolamento que o trabalho em turno de revezamento proporcionava a esses trabalhadores.

O Químico lembrou também que o adoecimento mental dos trabalhadores pode ser derivado de uma doença física, como as LER/DORT (Lesões por Esforços Repetitivos/Distúrbios Osteomusculares Relacionados ao Trabalho) ${ }^{\mathrm{c}}$, que foi produzida pelo trabalho. Assim como afirmam Silva et al. ${ }^{31}$, o Químico ressalta que os lesionados sofrem assédio moral interpessoal e organizacional, por meio de humilhações, exclusão e pressão dentro do ambiente de trabalho. Alguns trabalhadores não suportam viver sob essas condições e preferem pedir demissão, enquanto outros ultrapassam seus próprios limites, para tentar suportar tal situação, acarretando agravos à sua saúde mental.

O Bancário, o Petroleiro e o Metalúrgico também ressaltaram tal questão, além de apontarem a

c De acordo com Lima ${ }^{30}$, as LER/DORT consistem em lesões desencadeadas por movimentos repetitivos e rápidos, realizados pelos traba-

lhadores sob pressão, para aumentar a produção, que impactam no ritmo de trabalho e também na saúde mental do portador. 
organização do trabalho como principal responsável pelo adoecimento dos trabalhadores. A seguinte fala do Bancário exemplifica essa concepção:

\begin{abstract}
Na nossa opinião, o adoecimento acontece por conta da organização do trabalho, por conta dos processos de trabalho dentro dos bancos, da forma de se gerenciar o trabalho [...] Mas a gente tinha muitos bancários com LER/DORT também e vimos que, a partir da LER/DORT, o trabalhador também pode desenvolver um problema e um transtorno mental.
\end{abstract}

A partir das entrevistas, é possível notar que todos os participantes da pesquisa foram extremamente sensíveis à saúde mental do trabalhador, apontando negligência por parte das empresas e do Estado, e se mostrando incomodados com a atribuição de culpa individual aos trabalhadores por seus problemas de saúde. De acordo com Jackson Filho et al. ${ }^{32}$, a culpabilização da vítima, nesses casos, acaba por produzir grandes injustiças sociais. Os trabalhadores, em geral, são considerados, pela ideologia capitalista vigente, como pessoas de pouca responsabilidade, desprovidas de conhecimentos e educação. Considerando esses aspectos, os sindicalistas entrevistados destacaram a importância da conscientização dos trabalhadores para ações coletivas. A seguinte fala do Professor é bastante ilustrativa:

O professor vai adoecendo e muitas vezes ele não tem consciência de que ele está adoecendo por conta de suas condições de trabalho. Ele não atribui ao trabalho, ele atribui a outras questões [...] Tomar consciência de que as condições de trabalho e esse adoecimento aparentemente individual [...] é um problema coletivo, que não acomete só a ele, mas que acomete a ele também. Claro que ele vai procurar se cuidar, enfim, mas enquanto ele estiver submetido sistematicamente a condições de trabalho adversas, ele vai ter poucas chances, digamos assim, de ganhar imunidade emocional e física, para enfrentar. E o enfrentamento não é sozinho, o enfrentamento é coletivo.

Os representantes sindicais afirmam que tentam combater o olhar essencialmente individualizante com relação às causas do adoecimento e da culpabilização da vítima, mas ressaltam que isso é ainda mais difícil com relação aos problemas de saúde mental. Conforme afirma o Químico:

Se, para as empresas, uma LER/DORT não é por conta do trabalho, imagina então uma doença mental. Para as empresas, você adquire a LER/DORT através de um filho pequeno [por ter de carregá-lo], o filho é que é o culpado então [...]. Mas a doença mental é pior ainda. Faz nove anos que eu estou no sindicato e, somente num caso, nós conseguimos provar, diante da justiça, que o trabalhador adoeceu por conta do trabalho com a questão da doença mental.
O Bancário também traz um relato que revela a seriedade dos agravos à saúde mental no seu setor:

\begin{abstract}
Vemos na nossa experiência sindical trabalhadores que se afastam e conseguem um tratamento e recuperam parte da sua capacidade de trabalho. Mas tem outra parte dos trabalhadores que não consegue voltar ao local de trabalho, que ficam mais incapacitados. A gente tem casos de depressão, motivada por práticas de assédio moral, que viram uma síndrome do pânico. A pessoa não consegue nem pisar mais naquele local de trabalho. Então, nossa prática sindical, que não é muito rigorosa ou muito sistematizada, revela que os bancos não mexem um milímetro na questão da organização de trabalho e de formas de trabalhar, e isso sempre recai sobre a pessoa.
\end{abstract}

De acordo com os entrevistados, o trabalhador adoece por conta do trabalho e, quando busca auxílio em serviços públicos, sente-se ainda mais desamparado, pois o próprio Estado não consegue lhe dar o auxílio necessário e não reconhece o nexo do seu problema de saúde com o trabalho. Esse duplo desamparo, por parte da empresa e do Estado, é destacado especialmente pelo Bancário:

A situação que os bancos criam é de não querer assumir o trabalhador, não querer assumir a sua responsabilidade enquanto empregador, né? Isso também é outro fator de extremo desgaste mental, porque a pessoa se sente desamparada.

Em síntese, podemos dizer que todos os entrevistados mostraram possuir uma visão crítica sobre a relação entre as características do trabalho na atualidade e o comprometimento da saúde mental dos trabalhadores. A ideia da relação trabalho-saúde-doença como um "processo" de desgaste relacionado à organização e ao ambiente de trabalho, conforme defendem Laurell e Noriega ${ }^{13}$, pode ser identificada na fala de todos os entrevistados, ainda que nenhum deles tenha feito qualquer referência teórica nesse sentido. O mesmo ocorre com a ideia de "desgaste mental". Suas falas apontam aspectos relativos aos diferentes patamares destacados por Seligmann-Silva ${ }^{5}$ e destacam os componentes sociais, que costumam ser ignorados na visão predominante na sociedade.

Eles ainda defendem o papel dos sindicatos com relação à luta pela saúde dos trabalhadores, inclusive, porque, devemos lembrar, trata-se de sindicatos com histórico engajamento nesse campo. Mesmo apontando dificuldades para desenvolver ações de enfrentamento em um contexto bastante adverso, característico da contemporaneidade, eles apresentam possibilidades, conforme veremos a seguir. 


\section{Possibilidades de enfrentamento apresentadas pelos representantes sindicais}

Em relação às iniciativas que promovem o enfrentamento às questões de SMRT, podemos notar, pelo discurso dos entrevistados, que eles acreditam que a principal forma de atingir os trabalhadores e a sociedade como um todo é por meio da conscientização, rompendo com as concepções hegemônicas, que acabam por ser assimiladas por toda a sociedade, incluindo os próprios trabalhadores. Devemos ressaltar que, de acordo com Boltanski e Chiapello ${ }^{33}$, essas concepções predominantes configuram o "espírito do capitalismo” de cada época, o qual, por sua vez, pode ser definido como um "conjunto de crenças associadas à ordem capitalista, que contribui para justificar tal ordem e para sustentar, através da legitimação, os modos de ação e as disposições que são coerentes com ela”. Ainda, segundo os autores:

Enquanto ideologia dominante, o espírito do capitalismo tem, teoricamente, a capacidade de penetrar em um conjunto de representações mentais próprias de uma época determinada, de infiltrar-se nos discursos políticos e sindicais e de proporcionar representações legítimas e esquemas de pensamento aos jornalistas e investigadores, de tal forma que sua presença é, ao mesmo tempo, difusa e generalizada.

Trata-se, portanto, de uma questão que vai muito além da relação com os empregadores, trata-se de uma ideologia difundida por toda a sociedade.

Ainda segundo os autores, na contemporaneidade, estaríamos vivendo o "terceiro espírito do capitalismo”, o qual se vale da globalização e de novas tecnologias para promover uma ideologia que se pauta no individualismo e na competitividade, entre outras características. Nesse sentido, os entrevistados reconhecem que o movimento sindical pouco conseguiu avançar no enfrentamento dessas características que permeiam os diversos âmbitos da sociedade. Por outro lado, trazem algumas experiências significativas, principalmente no que se refere à busca do restabelecimento da união e da solidariedade entre os trabalhadores.

Todos os entrevistados destacaram a importância de promover ações que incentivem a união - seja dos próprios trabalhadores, como também de sindicatos e de outros âmbitos da sociedade - para conscientizar e combater as causas do adoecimento físico e/ ou mental dos trabalhadores e a maior parte deles aborda a importância de desenvolver ações para conseguir a aproximação dos trabalhadores. O Professor traz um exemplo interessante:

O sindicato dos professores, por conta até de uma iniciativa do Ministério da Cultura, se tornou um ponto de cultura aqui na cidade. Enquanto ponto de cultura, o sindicato promovia para os docentes e para os cidadãos da região, atividades culturais, oficinas de artesanato, de canto, oficinas culturais. Foi um momento em que o sindicato mais esteve com os docentes circulando lá dentro. Então, eu tendo a achar que essas iniciativas, que não são tidas como maçantes como uma assembleia, são atividades que atraem os docentes.

Já o Petroleiro afirmou que uma forma de enfrentamento seria a atuação dos sindicatos para o acolhimento dos trabalhadores que tiveram algum tipo de vivência negativa no trabalho ou que apenas queiram discutir coletivamente os problemas identificados. Essa proposta parece seguir na direção apontada por Bihr ${ }^{19}$, ou seja, incorporar questões que fazem sentido para os trabalhadores da base. Um exemplo significativo foi trazido pelo Bancário, ainda que a atividade apresentada não tenha se prolongado por muito tempo:

\begin{abstract}
Nós fundamos um grupo chamado Grupo de Ação Solidária em Saúde para discutir o trabalho [e o discutíamos] tanto individualmente quanto coletivamente. Foi uma experiência muito rica, pois foi nesse momento que nós conseguimos juntar os trabalhadores. E é sério, todas as reuniões que nós fizemos, lotavam o auditório, vinha muita gente [...]. O Grupo se tornou um espaço em que as pessoas conseguiam fazer terapia, porque elas conseguiam perceber, ali na coletividade, que o problema dela não era único, então eram muito interessantes as reuniões, porque a gente fazia palestra e tal. A gente procurava não tomar todo o tempo da reunião para deixar espaço para que eles falassem, e falavam.
\end{abstract}

Ressalta-se que, de forma geral, os entrevistados admitem que os sindicatos não conseguem resolver sozinhos as questões relativas à saúde, especialmente, à saúde mental dos trabalhadores. Para o Bancário, as ações voltadas para esse tema não devem se limitar aos sindicatos, mas devem contar com a presença do Estado, especialmente do setor da saúde. Para ele, as ferramentas existem, mas as estruturas de saúde pública ainda não estão preparadas para cuidar do trabalhador, seja em nível de promoção, prevenção e/ou tratamento. O Químico e o Professor mostraram estar de acordo com essa avaliação, pois ressaltam que a troca de experiência e a união dos sindicatos auxiliam em tais questões, mas se faz necessária uma forte parceria com o poder público, para haver algum avanço. Segundo o Bancário:

A gente tem muitos instrumentos do ponto de vista da legislação, vamos dizer assim. Por outro lado, têm as convenções da OIT, em que o Brasil é signatário, que entram por ordenamento jurídico. As ferramentas existem. Nós temos a RENAST, que é a Rede Nacional de Atenção Integral à Saúde do Trabalhador, temos os CERESTs, que têm a ver com a política da RENAST, você tem o Conselho Nacional de Saúde 
e, por sua vez, lá dentro, tem a CIST, que é a Comissão Intersetorial de Saúde do Trabalhador, que é só pra discutir a saúde do trabalhador. Só que você não consegue ter uma integração de tudo isso e [...] não chega na ponta [...]. Apesar da gente entender que o Estado tem vários instrumentos, não tem uma efetividade como nós necessitamos. A mão do Estado, a participação do Estado na saúde do trabalhador é fundamental.

Dois entrevistados relataram fatos que mostram que, nas últimas décadas, seus mais importantes parceiros no poder público para o enfrentamento de problemas relativos à saúde têm sido os Centros de Referência em Saúde do Trabalhador (CEREST). O Metalúrgico, por exemplo, é categórico ao afirmar que, nessa questão, o sindicato conta com o CEREST da sua cidade e ressalta que é o único órgão público com o qual se pode contar, o que acaba por sobrecarregá-lo. Ele afirma ainda que, socialmente, existe um ideário de que os serviços de saúde pública são demorados e ineficazes, o que não seria verdade.

O Bancário ressalta que não é possível esperar apenas ações do Estado e reforça que a conscientização dos trabalhadores é o que faria diferença na luta pelas questões da saúde. Para isso, afirma que, hoje em dia, as greves não são suficientes e que a visibilidade das ações deve ser ainda maior do que o que elas podem propiciar. O entrevistado refere-se a uma paralisação nos sistemas do banco que realmente comprometesse o lucro das empresas e não apenas alguns serviços para os usuários. Para ele, algo que afetasse os programas de tecnologia da informação seria uma ação mais eficaz.

Para o Químico, o enfrentamento, além da união dos sindicatos, deve dar-se também por meio da mídia, que auxiliaria na conscientização da população em geral sobre as questões de SMRT. Entretanto, ele não sabe dizer como conseguir isso em um contexto em que os meios de comunicação também pertencem, na grande maioria, a empresas privadas e, portanto, com interesse em propagar o "espírito do capitalismo" e não em conscientizar trabalhadores.

Para o Metalúrgico, a forma mais eficiente de lutar e combater certas questões, tal como o adoecimento relacionado ao trabalho, continua sendo "ir para as ruas”, referindo-se à greve. Ressaltou também outras medidas, como a realização de assembleias e a divulgação da causa em jornais e revistas. Contudo, frente aos demais entrevistados, vemos que essas medidas são mais tradicionais, podendo ser consideradas menos criativas diante de um contexto em que as empresas estão sempre criando novas formas de exploração e inibição da organização coletiva dos trabalhadores.
Ainda que apresentando diferentes propostas, todos os entrevistados foram unânimes em afirmar que a conscientização dos trabalhadores sobre as características do trabalho na atualidade e suas consequências para a saúde é fundamental. Tal perspectiva é corroborada pelo DIEESE, para o qual, a possibilidade do trabalhador intervir no processo saúde/ doença está diretamente relacionada à capacidade de intervenção sobre seu trabalho ${ }^{18}$. Nesse sentido, trabalhadores conscientes da sua exploração e da relação entre trabalho e saúde/doença poderiam se fortalecer coletivamente para conseguir intervir nas condições e nas formas de organização do trabalho, de modo a evitar o comprometimento da sua saúde.

Por outro lado, nesse mesmo documento do DIEESE, é possível perceber que a maior parte do movimento sindical brasileiro ainda tem suas reivindicações voltadas para questões salariais e de benefícios. Por isso, a SMRT ainda carece da conscientização dos próprios sindicatos. Com relação a esse aspecto, é importante dizer que alguns dos entrevistados, especialmente aqueles que estão inseridos no setor de saúde dos seus sindicatos, apontam, inclusive, a dificuldade de sensibilizar seus próprios colegas sindicalistas para questões relativas à saúde do trabalhador de um modo geral e, mais ainda, para aquelas relativas à saúde mental. Assim, apesar das ações citadas por eles, a pauta de reivindicações dos seus respectivos sindicatos, ainda que incluam aspectos relativos à saúde, acabam também por priorizar as questões que dizem respeito à remuneração nas negociações com as empresas.

Por isso, os entrevistados destacaram a importância da formação de sindicalistas para a prática sindical relativa à saúde, o que, segundo eles, favoreceria um olhar diferenciado frente à SMRT. O Professor afirmou que, muitas vezes, nas universidades, os professores sequer sabem o que o sindicato de sua categoria faz e as questões pelas quais ele luta. O Químico frisou, diversas vezes, a importância da formação de novos quadros nos sindicatos. O Bancário, por sua vez, possui discurso semelhante, dizendo que a saúde do trabalhador não pode estar dissociada da formação, sob a ótica dos trabalhadores, das centrais sindicais e de partidos políticos, ou seja, envolve tanto a formação acadêmica quanto profissional e política. Todavia, parece que, junto com a informação, é necessária a sensibilização para a temática da SMRT.

\section{Considerações finais}

O contato com os participantes propiciou rico conteúdo a ser analisado, já que os entrevistados trouxeram diversas reflexões e experiências 
vivenciadas dentro do movimento sindical, que ilustram bem como a atual conjuntura capitalista proporciona condições de trabalho precárias, que acabam por degradar o bem-estar dos trabalhadores, afetando sua saúde mental, já que as prioridades são o produto e a produção e não o trabalhador e sua saúde.

Frente a esse complexo contexto, os representantes sindicais destacaram as dificuldades enfrentadas diariamente para estabelecer o nexo causal entre adoecimento e trabalho e para adotarem ações de prevenção dos agravos à saúde. Em sintonia com a literatura crítica referente à saúde do trabalhador, além das condições físicas do ambiente de trabalho, da organização do trabalho e dos processos produtivos e das relações trabalhistas, eles também destacam características do atual "espírito do capitalismo", como individualidade e competição extrema, que têm consequências diretas sobre a subjetividade do trabalhador.

A conscientização, a solidariedade e a união dos trabalhadores e de alguns setores da sociedade são alguns dos principais meios de enfrentamento dessa temática, segundo os entrevistados, já que o adoecimento ainda é visto, hegemonicamente, como fruto de propensões individuais e genéticas, e não decorrente da forma como o trabalho é organizado e vivenciado. Contudo, por mais que esses sindicatos apresentem avanços e consigam construir medidas mais inovadoras e criativas para atingir os trabalhadores e favorecer a conscientização da sociedade sobre a saúde do trabalhador, fica difícil designar somente às entidades sindicais tamanha responsabilidade. É necessária uma aproximação dos diferentes movimentos sociais que lutem pela superação do modelo de sociedade imperante na contemporaneidade.
O que foi possível concluir é que, mesmo entre sindicalistas que se mostram conscientes da influência do trabalho sobre o processo saúde-doença mental e apresentam sensibilidade para seu enfrentamento, existe a constatação de uma enorme dificuldade para a adoção de ações sindicais efetivas nesse sentido. Tal constatação indica que o enfrentamento das condições que geram agravos à saúde mental dos trabalhadores é ainda um grande desafio a ser enfrentado.

Seria incorreto afirmar que os entrevistados desta pesquisa sejam representativos dos sindicatos em geral, visto que são sindicalistas que têm aproximação com a questão da saúde do trabalhador. Todavia, o objetivo desse texto não foi analisar as concepções e práticas de uma mostra representativa de sindicalistas sobre a relação entre saúde mental e trabalho e, sim, de alguns que já apresentam uma sensibilidade com relação à saúde do trabalhador. Cremos que essas reflexões possam servir de inspiração a outros sindicatos que ainda não priorizam as ações de prevenção da saúde mental dos trabalhadores, bem como de outros movimentos sociais.

Considerando esses aspectos, espera-se, com este artigo, propiciar uma reflexão acerca da SMRT enquanto um problema social, que deve ser mais bem discutido, a fim de proporcionarmos a conscientização da sociedade como um todo, incluindo os trabalhadores, os próprios sindicalistas, a academia, entre outras instâncias. Reconhecendo o problema, compreendendo suas causas sociais, poderemos avançar na busca de ações que evitem ou, ao menos, amenizem o sofrimento de um enorme - e crescente - contingente de trabalhadores.

\section{Contribuições de autoria}

As autoras contribuíram igualmente na concepção do estudo e no levantamento e interpretação de dados, na elaboração do manuscrito e na sua aprovação final.

\section{Referências}

1. Franco T, Druck G, Seligmann-Silva E. As novas relações de trabalho, o desgaste mental do trabalhador e os transtornos mentais no trabalho precarizado. Rev Bras Saúde Ocup. 2010;35(122):229-248.

2. Seligmann-Silva E, Bernardo MH, Maeno M, Kato M. O mundo contemporâneo do trabalho e a saúde mental do trabalhador. Rev Bras Saúde Ocup. 2010;35(122):187-191.
3. Linhart D. Modernisation et précarisation de la vie au travail. Papeles del CEIC [Internet]. 2009 mar [citado em 2016 nov 16];(1):1-19.

Disponível em: http://www.identidadcolectiva.es/ pdf/43.pdf

4. Sato L, Bernardo MH. Saúde mental e trabalho: os problemas que persistem. Ciênc Saúde Coletiva. 2005;10(4):869-878. 
5. Seligmann-Silva E. Trabalho e desgaste mental: o direito de ser dono de si mesmo. São Paulo: Cortez; 2011.

6. Lacaz FAC. O campo Saúde do Trabalhador: resgatando conhecimentos e práticas sobre as relações trabalho-saúde. Cad Saúde Pública. 2007;23(4):757-766.

7. Paparelli R. Grupo de enfrentamento do desgaste mental no trabalho bancário: discutindo saúde mental do trabalhador no sindicato. Rev Bras Saúde Ocup. 2011;36(123):139-146.

8. Harnois G, Gabriel P. Mental health and work: impact, issues and good practices. Geneva: World Health Organization; 2000. 77 p.

9. Ministério da Previdência Social. Cai número de acidentes de trabalho e aumenta afastamentos por transtornos mentais. Previdência em questão [Internet]. 2012 [citado em 2016 nov 16];(59) :12. Disponível em: http://www.previdencia.gov.br/ arquivos/office/4_120326-105114-231.pdf

10. Paparelli R, Sato L, Oliveira F. A saúde mental relacionada ao trabalho e os desafios aos profissionais da saúde. Rev Bras Saúde Ocup. 2011;36(123):118-127.

11. Bernardo MH. Trabalho duro, discurso flexível: uma análise das contradições do toyotismo a partir da vivência de trabalhadores. São Paulo: Expressão Popular; 2009.

12. Stecher A. El campo de investigación sobre transformaciones del trabajo, identidades y subjetividad en la modernidad contemporánea: apuntes desde Chile y América Latina. In: Stecher A, Godoy L, editores. Transformaciones del trabajo, subjetividad e identidades: lecturas psicosociales desde Chile y América Latina. Santiago: Ril Editores; 2014. p. 19-76.

13. Laurell AC, Noriega M. Processo de produção e saúde: trabalho e desgaste operário. São Paulo: Editora Hucitec; 1989.

14. Sennett R. A corrosão do caráter: consequências pessoais do trabalho no novo capitalismo. Rio de Janeiro: Record; 1999.

15. Rodrigues IJ. Estratégia operária e neocapitalismo. Tempo Soc. 2009;21(1):51-64. p. 61. (p. 61)

16. Rosso SD. Fragmentação sindical. Educar em Revista. 2013;(48):39-52.

17. Revista Consultor Jurídico. Terceirização enfraquece movimento sindical, diz juiz [Internet]. 2013 maio 14 [citado em 2016 nov 16]. Disponível em: http:/www.conjur.com.br/2013-mai-14/ terceirizacao-enfraquece-movimento-sindicalavalia-juiz-trabalho

18. Departamento Intersindical de Estatística e Estudos Socioeconômicos. Estudos e pesquisas: a saúde do trabalhador no processo de negociação coletiva no Brasil [Internet]. São Paulo: DIEESE; 2015 [citado em 2016 nov 16]. Disponível em: http://www.dieese.org.br/estudosepesquisas/2015/ estpesq76saudeTrabalhador.pdf

19. Bihr A. Da grande noite à alternativa: o movimento operário europeu em crise. São Paulo: Boitempo; 1998.

20. Hammersley M, Atkinson P. Etnografía: métodos de investigación. Barcelona: Paidós; 1994.

21. Duarte J. Entrevista em profundidade. In: Duarte J, Barros A. Métodos e técnicas de pesquisa em comunicação. 2a ed. São Paulo: Atlas; 2006. p. 62-83.

22. Minayo MCS. O desafio do conhecimento: pesquisa qualitativa em saúde. São Paulo: HucitecAbrasco; 1994.

23. Bernardo MH, Garbin AC. A atenção à saúde mental relacionada ao trabalho no SUS: desafios e possibilidades. Rev Bras Saúde Ocup. 2011;36(123):103-117.

24. Sznelwar LI, Uchida S. O trabalho bancário e a distorção comunicacional: quando a mentira é parte da tarefa. In: Sznelwar LI, organizador. Saúde dos bancários. São Paulo: Publisher Brasil: Gráfica Atitude; 2011. p. 105-125.

25. Bernardo MH. Produtivismo e precariedade subjetiva na universidade pública: o desgaste mental dos docentes. Psicol Soc. 2014; 26(n. spe):129-139.

26. Bruno WP. Bancários não são máquinas. In: Sznelwar LI, organizador. Saúde dos bancários. São Paulo: Publisher Brasil: Gráfica Atitude; 2011. p. 21-33.

27. Alvarez D, Figueiredo M, Rotenberg L. Aspectos do regime de embarque, turnos e gestão do trabalho em plataformas offshore da bacia de Campos (RJ) e sua relação com a saúde e segurança dos trabalhadores. Rev Bras Saúde Ocup. 2010;35(122):201-216.

28. Moreno CRC, Fischer FM, Rotenberg L. A saúde do trabalhador na sociedade 24 horas. São Paulo Perspec. 2003;17(1):34-46.

29. Praun L. Reestruturação produtiva, saúde e degradação do trabalho. Campinas: Papel Social; 2016.

30. Lima MEA. Saúde mental e LER: a dimensão psicológica das LER. Belo Horizonte: Mimeografado; 2000.

31. Silva EF, Oliveira KKM, Zambroni-de-Souza PC. Saúde mental do trabalhador: o assédio moral praticado contra trabalhadores com LER/DORT. Rev Bras Saúde Ocup. 2011;36(123):56-70.

32. Jackson Filho JM, Vilela RAG, Garcia EG, Almeida IM. Sobre a "aceitabilidade social" dos acidentes do trabalho e o inaceitável conceito de ato inseguro. Rev Bras Saúde Ocup. 2013;38(127):6-8.

33. Boltanski L, Chiapello E. Le nouvel esprit du capitalisme. Paris: Gallimard; 1999. 